\title{
EL NUEVO Código PROCESAL PENAL: DEL PROCESO INQUISITIVO AL PROCESO ACUSATORIO
}

MANUEL ARÁUZ ULLOA

Director del Bufete Jurídico y Profesor adjunto de Derecho Penal Universidad Centroamericana

\section{Introducción}

T a reciente aprobación de un nuevo Código Procesal Penal trae consigo cambios sustanciales Len la realidad procesal nicaragüense; en primer lugar, supone el rompimiento de un sistema violatorio de los derechos humanos que regía desde el año 1879 caracterizado por el imperio del principio inquisitivo, es decir, del establecimiento de un proceso penal. escrito. secreto, lento y. sobre todo, incierto en sus resultados: en segundo lugar, el nuevo Código Procesal Penal supone la plasmación y concreción de los derechos y garantías individuales establecidos en nuestra Constitución de lo cual deriva una tercera consecuencia, el estricto apego a los principios del debido proceso. que no son más que el respeto absoluto al conjunto de derechos y garantías que. normados por nuestra Constitución Política. tratan de garantiza la seguridad jurídica de la persona cuando ésta, por la comisión -supuesta- de un hecho delictivo, es obligada a someterse a un procedimiento que tiene por objeto determinar su responsabilidad en el hecho que se le imputa.

En la abrumadora mayoría de los estados modernos los conceptos proceso penal y debido proceso suelen identificarse como términos ligados de manera indisoluble. si bien puede existir proceso penal sin debido proceso, el aun vigente Código de Instrucción Criminal de 1879 es un ejemplo de esto, la tendencia es, como ya hemos apuntado, a hacer del proceso penal un mecanismo de realización de la justicia con absoluto respeto de los derechos y garantías individuales establecidos en la mayoría de las constituciones y tratados internacionales, ya que, para asegurar su eficacia se necesita. además de su establecimiento constitucional, la posibilidad de realización de esos mecanismos de ejecución y defensa. y esto sólo puede lograrse cuando expresamente los recoge la legislación ordinaria. De manera pues, que si el proceso penal es el conjunto de actividades y formas mediante las cuales los órganos competentes, observando ciertos requisitos. proveen, investigan, juzgan, aplican la ley penal en cada caso concreto, con el fin de obtener, emitir y ejecutar una sentencia judicial; este conjunto de actos, tendentes a la averiguación y sanción de las conductas tipificadas como delitos, deben realizarse en aras de la seguridad jurídica del ciudadano, atendiendo a principios como los de presunción de inocencia. del juez 
natural, de inviolabilidad de la defensa. de legalidad, de retroactividad de la ley más favorable, de publicidad, oralidad y inmediación, entre otros.

El llamado proceso legal o debido proceso tiene una pluralidad de elementos que giran todos en torno a la premisa de que a nadie se le negará la oportunidad de ser oído, sin demora o perjuicio, ante un juez imparcial, incluye también el derecho a ser informado sin demora de la naturaleza y causa de la acusación, tiempo para preparar la defensa. disponer de la asesoría jurídica, la posibilidad de obtener testigos. el derecho de no ser obligado a declarar contra si mismo, y la asistencia de un intérprete si fuere necesario.

Además de lo anterior, se traduce en el libre ejercicio del derecho a un juicio equitativo, del derecho a que la causa sea vista públicamente. a que la causa sea vista en un plazo razonable por un tribunal independiente. imparcial y establecido por la ley, el derecho a la presunción de inocencia, a ser informado sin demora de la naturaleza y causa de la acusación, a disponer de tiempo y de las facilidades y medios necesarios para la defensa. a hallarse presente en el proceso. defenderse personalmente y a contar con un defensor, a no ser obligado a declarar contra si mismo ni a confesarse culpable y del derecho al juez legal o natural.

Las diferencias entre un proceso penal respetuoso de las garantías del denominado debido proceso y otro que las conculca son fáciles de percibir, basta con saber si se ha establecido en la ley el denostado proceso penal inquisitivo o, por el contrario. estamos ante un proceso penal acusatorio.

\section{La inquisición en el proceso penal}

La inquisición es el sistema de enjuiciamiento penal que responde a la concepción absolutista del poder. a la idea extrema sobre el valor de la autoridad. un proceso penal en el que la centralización del poder y todos los atributos que concede la soberanía se reúnen en una única mano, en la mano del Juez, del Monarca o del Señor. Afirma MAIER que desde el punto de vista procesal al principio inquisitivo se le ha traducido como "aquel procedimiento que reduce al imputado a un mero objeto de investigación. con lo cual pierde su consideración como sujeto de derechos y adquiere el carácter de objeto procesal ${ }^{* 1}$.

Cuando se analiza si un ordenamiento procesal penal está inspirado por el principio inquisitivo. se hace en relación contraria al principio acusatorio -del que nos ocuparemos luego-. ZAFFARONI ${ }^{2}$ ha señalado "que si en el proceso penal se encuentran defendidos en grado extremo los intereses de la colectividad el proceso será inquisitivo; por el contrario si los intereses defendidos son en su mayoría los individuales el proceso será acusatorio“. De la misma manera, tanto el principio inquisitivo como el acusatorio se caracterizan por la diferente asignación de funciones procesales. así, si la función de acusador. defensor y juez, es encomendada a un órgano propio e independiente

MAIER, DPPA, 1989, pág. 209.

ZAFFARONI (en: Galván González. compilador), Archivo de DP. 1993, pág. 38. 
(I proceso será acusatorio. Si las tres funciones están encomendadas en manos de una sola persona, lc un mismo órgano que es el Juez, el proceso será inquisitivo.

Muchos han señalado que la naturaleza del proceso penal establecido por el Código de Instrucción Criminal de 1879 es la de un proceso mixto, es decir, que tiene parte de acusatorio y parte de inquisitivo ${ }^{3}$, pese a todo, y como lo apunta BINDER $^{4}$ - no puede ocultarse que la característica predominante en nuestro proceso penal es la de que la mayoría de los delitos que llegan a conocimiento del órgano jurisdiccional son perseguibles de oficio, son casos en los que cl Juez procede a la averiguación del delito o falta y del delincuente, excitado por noticias extrajudiciales o por queja de la parte agraviada, "sin mostrarse parte" (art. 30 In.); la enorme

' Si se quiere explicar en qué consiste el proceso mixto se dirá que la persecución penal y averiguación de la verdad comprendidas como metas absolutas del principio inquisitivo se mezclan con los valores o atributos de la personalidad humana. Los atributos señalados son traducidos como reglas y garantías de derechos individuales. Sin embargo, al tratar de conciliar los dos procedimientos se asumió que era necesario dividir el procedimiento en dos períodos principales enlazados por uno intermedio: el primero es una investigación a manera inquisitiva, el segundo busca asegurar la seriedad y pulcritud del proceso pronunciando una sentencia (interlocutoria) antes de convocar al juicio público, el tercero, imitando formalmente el juicio acusatorio, consiste, principalmente, en un debate público y oral.

Las principales características de este sistema son:

a. La persecución penal ejercida por tribunales con fuerte participación popular.

b. La persecución penal está en manos de un órgano del Estado y de manera excepcional en manos de los particulares.

c. El imputado es un sujeto de derecho que actúa en un papel pasivo respecto del proceso (en otras palabras no es un sujeto de derecho sino un objeto procesal).

d. El procedimiento es dividido en dos períodos principales, enlazados por uno intermedio: el primero una investigación inquisitiva, un intermedio y un tercero o plenario formalmente (no materialmente) acusatorio.

e. El fallo del Juez o tribunal según sea el caso de Intima Convicción a bajo reglas de la llamada Prueba Legal o Tasada; en aquellos que llevan como medio de valoración la Sana Crítica pronuncian en el fondo una sentencia de Intima Convicción acomodada a esas reglas.

En los términos señalados debe analizarse si en realidad el proceso mixto participa de la naturaleza acusatoria o solamente comporta la forma inquisitiva. A este respecto la doctrina (BINDER. MAIER. ZAFFARONI) ha respondido que no puede señalarse como proceso mixto aquel proceso cuyo único indicio acusatorio es el impulso procesal y la resolución de la causa por un tribunal de jurados, pues ello no hace desaparecer su naturaleza inquisitiva.

Para que un proceso penal pueda considerarse comn mixto debe en principio acordarse la etapa de la investigación a un órgano jurisdiccional especializado. distinto del juez de la causa, igualmente en la fase plenaria debe primar sobre todo la oralidad y la publicidad: debe de garantizar además la inmediación del Juez o Tribunal desde el inicio del plenario donde necesariamente deben reproducirse las pruebas de la fase de instrucción so pena de tenerlas por inexistentes. Con base en lo antes expuesto acojo lo apuntado por BINDER quien ha señalado que la naturaleza del proceso penal nicaraguiense es eminentemente inquisitiva: que nuestro proceso penal ha conservado la estructura clásica del procedimiento mixto o. mejor dicho. del procedimiento inquisitivo reformado "pues como señalé, detrás del llamado proceso mixto se esconde la naturaleza procesal inquisitiva” (Así, BINDER en la ponencia que presentara el día 21 de abril de 1994. en la Universidad Centroamericana de Managua).

BINDER, Introducción al DPP. 1993, pág. 116. 
responsabilidad que recae sobre el Juez -acaso no coincidente con lo que BINDER recientemente ha denominado el "Poder" en el Poder Judicial ${ }^{5}$ - es la de investigar, de recoger pruebas y tratar por todos los medios de encontrar o no un delincuente tal y como lo haría cualquiera de las partes procesales. En el proceso penal inquisitivo la mera noticia criminis, constituye el elemento clásico de impulso procesal. con él, el Juez inicia de oficio las investigaciones ${ }^{6}$, y lleva el proceso adelante respecto de una sola parte (el imputado), frente a la cual el juez investiga, y por fin, dicta sentencia ${ }^{7}$.

Otro rasgo de la forma inquisitiva en nuestro proceso penal es el carácter escrito de las actuaciones ${ }^{\mathrm{R}}$. lo que además de permitir una revisión de la cuestión en segunda instancia y aún en casación, compensa -y limita- los grandes poderes del juez inquisidor, que dicta sentencia de primer grado, basándose en sus averiguaciones (en el proceso sumario y en el sumario previo a la sentencia interlocutoria y en la misma sentencia interlocutoria) o luego del veredicto condenatorio del Tribunal de Jurados (en el juicio ordinario). Cuestión distinta es la de si la propia legislación concede o no la facultad de apelar del veredicto del jurado, en nuestra realidad. siendo que el tribunal de jurados falla de acuerdo con su "conciencia". tal posibilidad, en lo que al verédicto mismo se refiere, está vedada a las partes, todo ello -de lo que espero ocuparme en un futuro trabajo- nos induce a pensar en la posibilidad de que nuestro actual sistema de jurados esté también impregnado del poder absoluto -sin medida- de la inquisición.

\section{El juicio acusatorio}

El principio acusatorio, que como veremos inspira de forma determinante el nuevo Código Procesal Penal. exige que se promueva y sostenga. por una parte distinta del juez. una acusación o pretensión punitiva para que pueda abrirse el juicio penal y, en su caso, pueda condenarse al reo. Como ha apuntado MAIER "La característica fundamental del enjuiciamiento acusatorio reside en la división de los poderes que se ejercen en el proceso, por un lado el acusador. que persigue penalmente y ejerce el poder requirente, por el otro el imputado. quien puede resistir la imputación ejerciendo el derecho de defenderse $\mathrm{y}$, finalmente, el tribunal que tiene en sus manos el poder de decidir. El principio fundamental que da nombre al sistema acusatorio se afirma en la exigencia de un tribunal para decidir el pleito y los límites de su decisión están condicionados al reclamo o acusación ${ }^{* 9}$.

\footnotetext{
"Véase, la introducción que se realiza en el libro de ARÁUZ/ MORENO "La imagen de la Justicia". Editorial UCA. 2001.

${ }^{6}$ En este tipo de proceso el juez instructor, como director y artífice de la investigación, puede acordar todas las diligencias que considere convenientes o útiles para la comprobación del delito e identificación de los culpables, pudiendo las partes personadas colaborar en la instrucción, pidiendo la práctica de las diligencias que estimen oportunas, y que deben, en todo caso, acordarse por el Juez si las considera conducentes (art. 55, 184 In.).

7 Véase, DE LA OLIVA SANTOS y otros, DPP, 1993, pág. 37.

$\$$ Arto. 4 In.- El juicio criminal ordinario es escrito y se divide en dos partes: juicio de instrucción o informativo, y juicio plenario: el sumario es verbal y sólo tiene juicio de instrucción.

9 MAIER, DPPA, 1989, pág. 207.
} 
El artículo 10 del nuevo Código Procesal Penal recoge como pilar fundamental de su articulado, dando cumplimiento así a una de las aspiraciones básicas del proceso de reforma, el denominado principio acusatorio, al señalar: "el ejercicio de la acción penal es distinto del de la función jurisdiccional. En consecuencia, los jueces no podrán proceder a la investigación, persecución ni acusación de ilícitos penales. No existirá proceso penal por delito sin acusación formulada por el Ministerio Público, el acusador particular o el querellante en los casos y en la forma prescritos en el presente Código".

Cuál es la diferencia entre lo establecido por el nuevo Código y lo que señala el Código de Instrucción Criminal de 1879, se preguntarán algunos. Pues bien, en lo que a la acusación se refiere, es decir al ejercicio de la acción penal a través del instrumento de la acusación, no existe ninguna diferencia, tanto en el Código vigente como en el recién aprobado puede presentar la acusación el Ministerio Público, las partes ofendidas o perjudicadas por el hecho delictivo y cualquier otro ciudadano, salvo la excepción de los delitos de orden privado en los que la facultad de acusar corresponde sólo al perjudicado o agraviado; de manera pues que el contenido de los artículos 36 y siguientes del In se corresponden -en cuanto al fondo- con los artículos 10, 77 y siguientes del nuevo Código.

La diferencia entre ambos códigos reside en otro mecanismo de iniciación del proceso, el de la denuncia, afortunadamente desterrada del articulado de la nueva ley. Es la existencia de la denuncia -aunque también todo el sistema procesal penal aún vigente- lo que, pese a la existencia de la acusación como mecanismo de iniciación del proceso. impide hablar del establecimiento del principio acusatorio, ni siquiera. como ya se dijo, de un sistema mixto; la inquisición se manifiesta en la facultad del judicial de continuar los procedimientos e investigaciones de aquellos delitos que denunciados o acusados dieran lugar al procedimiento de oficio.

Dicho lo anterior podemos adelantar que la naturaleza de un determinado sistema procesal puede observarse fácilmente desde el inicio mismo del procedimiento; así, mientras el inconstitucional proceso inquisitivo contiene un alto grado de oficialidad ( $u$ oficiosidad), el proceso penal acusatorio lo restringe al máximo.

\section{Principio de oficialidad y el nuevo sistema acusatorio}

El principio de oficialidad se refiere a aquel criterio derivado de un interés público predominante marcado por la ley, por el cual el proceso, su objeto. los actos procesales y la sentencia no están subordinados al poder de disposición de los sujetos jurídicos en relación con la tutela de sus derechos e intereses legítimos, sino que el inicio del proceso depende de que aquél interés público se ponga de manifiesto ante el Tribunal por cualquier persona ${ }^{10}$; lo importante, en consecuencia. no es la voluntad de las partes, sino la existencia de un interés público ${ }^{11}$ que obligue a una

10) DE LA OLIVA SANTOS y otros, DPP, 1993, pág. 8.

11 En este sentido, De la Oliva Santos y otros, en DPP. 1993, expresa que "para el principio de oficialidad, lo importante es que en el delito aparezca el interés público de no omitir pronunciamiento, que se conozca el hecho, ¿ante quién y cómo sucedió? ¿por quién y de qué manera?, para que aparezca inmediatamente ante el Ministerio Fiscal y ante el Órgano Jurisdiccional”. 
respuesta jurídico-penal con relación al delito o falta cometido, basta conque cualquier persona, incluido el juez, tenga noticia del acto delictivo para dar por iniciado el proceso penal correspondiente.

En el aún vigente Código de Instrucción Criminal de 1879 el principio de oficialidad es la nota característica, se autoriza el ejercicio de la acción penal, por una parte, a la Policía Nacional quien está facultada por la ley para iniciar las investigaciones por denuncia de los ciudadanos, por evidente urgencia o por caso de flagrante delito, a fin de remitirlas -luego de haber instruido la causa- a los Tribunales establecidos por la ley para la tramitación de las causas criminales (art. 29 y 31 In); por otra, también puede dar inicio por denuncia o acusación presentada por el Ministerio Público, de la misma manera la Procuraduría General de la República puede presentar denuncia o acusación en todos aquellos casos en los que figuren como ofendidos el Estado, las municipalidades y las instituciones autónomas o semi-autónomas; también se puede dar inicio al proceso penal por denuncia o acusación presentada por los particulares ${ }^{12}$ ante el propio $\mathrm{Juez}^{13} \mathrm{y}$, por si esto fuera poco, cualquier Juez de lo criminal puede proceder de oficio a la averiguación y sanción de los delitos y faltas penales siempre que la ley no exigiere querella, denuncia o consentimiento de la parte agraviada, o de sus representantes legales.

La consecuencia fundamental del exceso de oficialidad $u$ oficiosidad es, por una parte, la proliferación de denuncias criminales por hechos de poca relevancia. los denominados delitos bagatela, que bien podían ser resueltos en instancias distintas al costoso engranaje procesal, por otro lado, en algunas ocasiones se recurre a la denuncia como un mero mecanismo de coacción e intimidación $o$, en su caso, como una mera demostración de $\operatorname{poder}^{14}$; derivado de lo anterior no debe ser una sorpresa que algunos tribunales de la República tramiten, o intenten tramitar, casi dos mil causas por año, lo que ha llegado a disparar a niveles ciertamente alarmantes los índices de retardación de justicia, conculcando así, otra de las garantías del debido proceso "el de no retardación y celeridad procesal".

El sistema acusatorio que introduce la nueva ley acaba de un tajo con la oficiosidad, al menos la oficiosidad directa -aquella que convierte al Juez en sujeto activo del proceso- pues queda a salvo la obligación de la Policía Nacional y del Ministerio Público de perseguir e investigar los delitos -de orden público- que se cometan ${ }^{15}$; el nuevo sistema, lejos de establecer el monopolio de la

12 Acorde con el artículo 33 del Código de Instrucción Criminal de la República, cualquier persona podrá denunciar un delito o falta de las que dan lugar a procedimiento de oficio.

${ }^{13}$ Se trata de lo que en doctrina se conoce como el ejercicio de la denominada acción popular que se caracteriza por la la facultad que tiene cualquier persona de interponer, ante el tribunal competente, denuncia o acusación por la comisión de hechos que constituyan delito o falta sancionadas con una pena por el Derecho Penal vigente al momento de la comisión del acto. La ley concede a todo nicaragüense acción para acusar y denunciar todo delito o falta que da lugar a procedimiento de oficio, a excepción de las personas a quienes ella misma prohíbe este derecho (véase nota anterior).

${ }^{14} \mathrm{Al}$ respecto, véase mi artículo de opinión "Delito de desacato y el caso de las mantas", publicado en el Diario La Prensa del 31 de julio del 2001.

${ }^{15}$ Téngase en cuenta que el sistema acusatorio no supone la prohibición de denunciar. a lo que se refiere es que sólo a través de la acusación es que un Juez debe dar lugar a la iniciación del proceso, el ciudadano 
acción penal como algunos han sostenido recordando el viejo decreto 1130 de $1982^{16}$, garantiza que la parte ofendida -el ciudadano particular, la víctima o la sociedad- pueda acudir ante los tribunales de la República a interponer la correspondiente acusación criminal.

Tres son entonces las vías por las que una acusación puede llegar a conocimiento del Juez. La primera, a través de escrito acusatorio presentado por el Ministerio Público ${ }^{17}$. La segunda, por acusación particular en todos aquellos delitos de acción pública lo que, según lo establecido por el artículo 78 del nuevo Código Procesal Penal. podrá hacerse de tres maneras: adhiriéndose a la acusación prestitada por el Ministerio Público; interponiendo un escrito de acusación autónomo que cumpla los requisitos del artículo 77 , formulando cargos y ofreciendo elementos de convicción distintos de los presentados por aquel, o acusando directamente cuando el fiscal decline hacerlo, en la forma y en los términos previstos por la ley. La tercera es por medio de la presentación de querella en los delitos de acción privada la que debe ser presentada por escrito. personalmente o por apoderado especial, debiendo reunir además -so pena de inadmisibilidad- un sinnúmero de requisitos que la propia ley señala en el artículo $79^{18}$.

es libre de denunciar la comisión de cualquier delito sólo que -según lo establecido por el artículo 222 y siguientes del nuevo Código Procesal Penal- tal denuncia debe presentarse ante la autoridad policial o ante el Ministerio Público.

16 Publicado en el diario Oficial La Gaceta No. 263 del 10 de noviembre de 1982.

${ }^{17}$ Según el artículo 77 del nuevo Código Procesal Penal, el escrito de acusación deberá contener:

I. Nombre del tribunal al que se dirige la acusación:

2. Nombre y cargo del fiscal:

3. El nombre y generales de ley del acusado, si se conocen, o los datos que sirvan para identificación:

4. Nombre y generales de ley o datos que sirvan para la identificación del ofendido o víctima, si se conocen:

5. La relación clara, precisa, específica y circunstanciada del hecho punible, la participación del acusado en él, su posible calificación legal, y los elementos de convicción que la sustentan disponibles en el momento, $y$,

6. La solicitud de trámite.

Cuando el Ministerio Público, en razón de la exención de responsabilidad criminal de una persona conforme lo establecido en el Código Penal, estime que sólo corresponde aplicar una medida de seguridad, así lo solicitará.

is Estos requisitos son:

1. Nombre del tribunal al que se dirige la querella:

2. Nombre, generales de ley y número de cédula de identidad del querellante y, en su caso, también los de su apoderado:

3. Nombre, generales de ley del querellado o, si se ignoran, cualquier dato o descripción que sirva para identificarlo;

4. La relación clara, precisa, circunstanciada y específica del hecho punible, la participación del querellado en él y su posible calificación legal, $y$,

5. La solicitud de trámite y demás peticiones.

El escrito de querella deberá ir acompañado del listado de los medios de prueba de que se dispone con indicación expresa de los extremos sobre los que versará esa prueba; deberá acompañarse la prueba documental. 


\section{Principio de no retardación y celeridad procesal}

Desde el punto de vista doctrinal el proceso no debe tener una duración desmedida o indeterminada. Lograr que la tramitación de un proceso lo sea en un tiempo razonable es de todo punto de vista necesario. Consciente de esa necesidad nuestra Constitución Política ha consagrado como una garantía del procesado el derecho a ser juzgado sin dilaciones por un tribunal competente establecido por la ley (art. 34 inciso $2 \mathrm{Cn}$.).

El fenómeno de la retardación de justicia, de arraigo en nuestro medio -lamentablemente-, trae como consecuencia un alto índice de reos sin condena que se encuentran en calidad de encausados bajo prisión preventiva, agravándose su situación toda vez que se encuentran amparados por el principio de presunción de inocencia. Las causas de la retardación en la administración de justicia son diversas y variadas, a veces. son debidas a la labor entorpecedora de las partes, o de una de ellas, que piensa que le resulta conveniente una lenta y dificultosa tramitación de la causa; en tal caso, a nuestro juicio, no queda afectado el derecho fundamental que nos ocupa. ya que las excepciones y recursos utilizados por las partes se encuentran establecidos por la ley para ser usados por las partes de cara a la afectiva protección de sus derechos.

Las dilaciones indebidas, que afectan el proceso penaì y vulneran la Constitución en su artículo 34 inciso 2, son aquellas achacables al órgano jurisdiccional por causas objetivas que reflejan indiferencia o negligencia en el titular o titulares de los órganos jurisdiccionales. o en el personal al servicio de la Administración de Justicia. En nuestro proceso penal las dilaciones indebidas se manifiestan en el hecho de que se deje transcurrir un plazo razonable ${ }^{19}$ sin ser juzgada o sin resolverse una causa penal, ello se produce normalmente cuando no se realizan los actos procesales en el plazo que la ley establece, cuando el titular de un órgano jurisdiccional, el representante del Ministerio Público o las partes, no ajustan su actividad. a la legalidad.

Para combatir la retardación en la administración de la justicia la legislación vigente otorga a los superiores del titular del órgano remiso en administrar justicia. la facultad de condenar en la sentencia a los subalternos de los juzgados que hubieren retardado sin motivo ostensible las causas, o que hubieren cometido faltas que merezcan castigo y que aparezcan del proceso, asimismo aquellos que maliciosamente o por negligencia retardaren la remisión de los autos a sus destinos. serán responsables como reos de retardo de la pronta administración de justicia (art. 325,610 In.). Igualmente los funcionarios judiciales que intervinieren en los juicios criminales y retardan alguno de sus trámites, no ejecutándolos o no haciéndolos ejecutar en los términos establecidos por la Ley sin motivos razonables, serán irremisiblemente castigados por los tribunales superiores como rẹos de retardación de administración de justicia (art. 611 In.).

\footnotetext{
${ }^{19}$ Para valorar el plazo razonable, hay que ceñirse bien a los datos objetivos que nos ofrece el proceso (no es lo mismo la tramitación de una causa compleja que la tramitación de una causa simple) pero también se han de tener en cuenta los plazos que la ley señala para producir actos concretos como por ejemplo dictar el auto de procesamiento.
} 
La nueva regulación procesal señala, como principio general, el derecho del ciudadano a que se le garantice una justicia ágil y pronta, sin dilaciones indebidas, es decir, un sistema de justicia en el que los jueces y el Ministerio Público hagan prevalecer, bajo su responsabilidad, "la realización pronta. transparente y efectiva de la justicia", atendiendo a que es derecho de toda persona acusada en un proceso penal el de "obtener una resolución en un plazo razonable, sin formalismos que perturben sus garantías constitucionales"20. Además de lo anterior, el artículo $133 \mathrm{CPr}$. concede a las partes la posibilidad de demandar urgente despacho ante el funcionario que violente los plazos establecidos, y de no obtener respuesta, podrá presentarse una queja por retardo ante la Inspectoría General del Ministerio Público o la Comisión de Régimen Disciplinario de la Corte Suprema de Justicia.

El nuevo Código Procesal Penal no se conforma, sin embargo. con la mera posibilidad de introducir una queja ante términos más o menos inciertos como los utilizados por el Código de Instrucción Criminal de 1879, por el contrario. es taxativo en señalar plazos concretos para la duración del proceso. distinguiendo entre los casos normales ${ }^{21}$ y aquellos de tramitación compleja ${ }^{22}$.

\section{El derecho a un juicio previo como derivación expresa del principio de legalidad}

Aunque es en sede del Derecho Penal sustantivo donde más se ha hablado del principio de legalidad y que desde la ilustración nos viene dado a través del aforismo nullum crimen nullum poena nullum crimen sine lege, es también usual que a éste se le añada lo que se ha denominado "el principio de legalidad procesal". Desde el punto de vista penal se establece que todo procesado tiene derecho, en igualdad de condiciones, a no ser procesado ni condenado por acto $u$ omisión que, al tiempo de cometerse, no esté previamente calificado en la ley de manera expresa e inequívoca como punible, ni sancionado con pena no prevista en la ley (art. 34 inciso $11 \mathrm{Cn}$.). En los mismos términos se expresa el principio desde el punto de vista procesal al señalar que no podrá imponerse pena o medida de seguridad por la comisión de un delito o falta, si no a través de un procedimiento establecido previamente por la ley.

Con el establecimiento del principio de legalidad desde la norma Constitucional se ha interpretado que dicha garantía se refiere a la exigencia de una sentencia previa, en el sentido que no puede existir una condena que no sea el resultado de un juicio previo y lógico, expresado en una sentencia debidamente fundamentada.

Está normado por la Constitución de la nación que la administración de justicia garantiza el Principio de Legalidad: protege y tutela los derechos humanos mediante la aplicación de la ley en asuntos o procesos de su competencia, de ello se desprende que en los tribunales debe aplicarse el Principio de Legalidad por mandato expreso de la norma constitucional (art. $160 \mathrm{Cn}$.). El artículo 34 de nuestra Constitución Política establece:

\footnotetext{
20) Cfr. Art. 8 CPr.

${ }^{21}$ Véase el artículo $134 \mathrm{CPr}$.

22 Cfr. artículo $135 \mathrm{CPr}$.
} 
“Todo procesado tiene derecho, en igualdad de condiciones, a las siguientes garantías mínimas:

Inciso 2) A ser juzgado sin dilaciones por tribunal competente establecido por la ley. No hay fuero atractivo. Nadie puede ser sustraído de su juez competente ni llevado a jurisdicción de excepción".

En otros apartados la Carta Magna establece la obligación de tener en cuenta el Principio de Legalidad desde el momento en que la persona es detenida por la autoridad so pena de hacerse reo de detención ilegal (art. $33 \mathrm{Cn}$.). Cuando la garantía constitucional hace referencia a una ley anterior al hecho del proceso, no sólo está dando pautas concretas acerca de qué ley se debe utilizar para juzgar el caso. sino que nos indica que debe existir necesariamente un proceso y que ese proceso se rige por la ley anterior al hecho que es su objeto.

Como no podía ser de otra manera. pues se trata de la concreción en una ley ordinaria de los derechos y garantías consagrados en nuestra Constitución, el nuevo Código Procesal Penal da una enorme trascendencia al principio de legalidad procesal, estableciéndolo además como primera norma del articulado, señalando:

Artículo 1. Principio de legalidad. "Nadie podrá ser condenado a una pena o sometido a una medida de seguridad, sino mediante una sentencia firme. dictada por un tribunal competente en un proceso conforme a los derechos y garantías consagrados en la Constitución Política, a las disposiciones de este Código y a los tratados. convenios y acuerdos internacionales suscritos y ratificados por la República".

La garantía del Principio de Legalidad o Juicio Previo, es una fórmula sintética en la que está contenida una limitación objetiva al poder penal del Estado y una limitación subjetiva al ejercicio de ese poder. Se dice quie es una fórmula sintética porque expresa el punto de máxima eficacia de todas las garantías procesales. Como señala BINDER $^{23}$, el juicio previo es el punto de máxima concentración de la fuerza protectora de las garantías de defensa, inocencia. inviolabilidad de la intimidad, inmediación, publicidad, etcétera.

\section{Principio de oportunidad}

Según MAIER ${ }^{24}$. oportunidad significa. en este contexto, la posibilidad de que los órganos públicos, a quienes se les encomienda la persecución penal, prescindan de ella. en presencia de la noticia de un hecho punible o. inclusive, frente a la prueba más o menos completa de su perpetración. formal o informalmente. temporal o definitivamente, condicionada o incondicionalmente, por motivos de utilidad social o razones político criminales.

Otros autores señalan que por principio de oportunidad se entiende la facultad de las partes de asistir, promover y decidir sobre las fases del proceso penal, se trata de brindar a las partes, la

${ }^{23}$ BINDER, Introducción al DPP, 1993, pág. 115.

${ }^{24}$ MAIER, DPPA, 1989, pág. 556. 
oportunidad de decir y hacer en su defensa aquello que sea razonable y oportuno. La fundamentación histórica del principio de oportunidad se ha dado por una necesidad social. ya que, mientras el discurso jurídico penal mantiene el principio de legalidad como criterio de justicia rector de la persecución penal, del otro lado el de oportunidad, normado o no, selecciona conductas de diversas maneras con el objeto y el acuerdo de prescindir de la persecución penal ya sea en interés de las partes o por ausencia de un interés público que obligue a dicha persecución.

En las legislaciones modernas en las que se ha establecido el principio de oportunidad lo han hecho como una excepción del principio de legalidad, más aún han obligado a que los criterios de oportunidad sean determinados legislativamente a modo de autorizaciones para prescindir de la persecución penal en ciertos casos definidos por la ley -esto es precisamente lo que ha sucedido con la reciente aprobación del nuevo Código Procesal-.

Hasta la actualidad, y lo que queda de vigencia del Código de Instrucción Criminal, en nuestra legislación el principio de oportunidad ha estado mermado por el principio inquisitivo, el Juez realiza las investigaciones y averiguaciones necesarias al esclarecimiento del acto delictivo con independencia de si la parte agraviada -llámese víctima o perjudicado- participa o no de tales investigaciones; en este tipo de procesos, en donde la mayoría de los delitos son perseguibles de oficio, sólo queda a las partes la oportunidad de personarse en el proceso en el estado en que lo encuentren pues, tanto el ofendido como el imputado son tomados como parte en el proceso y podrán intervenir en todas sus etapas sin que por esto pueda disponer de ellas; al procesado -por su especial posición- debe garantizársele su intervención desde el inicio del proceso, so pena de nulidad por indefensión (art. 34 inciso 4 y 11 in fine $\mathrm{Cn}$.), no sucede lo mismo con la intervención de la víctima u ofendido por el delito, con o sin ellos el proceso continúa. Distinta es la situación cuando se trata de delitos perseguibles a instancia de parte, en ellos, a tenor del principio de oportunidad, las partes pueden promover la acción penal e impulsar los actos procesales establecidos por la ley, así como disponer sobre su curso; es decir que en cualquier momento pueden desistir de la acción intentada, finalizando con ello el proceso penal. Este es el único indicio que sobre el principio de oportunidad encontramos en el aún vigente sistema procesal penal.

Con la aprobación del nuevo Código Procesal Penal las cosas han cambiado muy sensiblemente, el artículo 14 del texto de referencia nos adelanta el establecimiento expreso del principio de oportunidad -desarrollado en artículos posteriores- señalando textualmente que, en los casos taxativamente determinados, "el Ministerio Público podrá ofrecer al acusado medidas alternativas a la persecución penal o limitarla a alguna o algunas infracciones o personas que participaron en el hecho punible" sin olvidarse de señalar que la efectividad del acuerdo que se adopte requerirá la aprobación del juez competente.

El breve enunciado realizado en el artículo 14 encuentra una mayor concreción en los artículos 55 al 68 inclusive, en ellos se señalan cuatro formas distintas de materializar el principio de oportunidad, a través de la mediación, de la prescindencia de la acción, del acuerdo y de la suspensión condicional de la persecución. No conviene - por el espacio limitado del que disponemos- entrar a estudiar cada una de estas manifestaciones, si merece la pena, en cambio, 
apuntar la excepción realizada por el artículo 55 del nuevo Código que determina la no aplicación del principio de oportunidad cuando se trate de delitos contra el Estado o cometidos con ocasión del ejercicio de sus funciones por funcionarios nombrados por el Presidente de la República o la Asamblea Nacional o por los que hayan sido electos popularmente o sean funcionarios de confianza.

\section{Principio de publicidad}

Nuestra Constitución Política, en la parte final del artículo 34, proclama que el proceso penal deberá ser público. El acceso de la prensa y el público en general podrá ser limitado por consideraciones de moral y orden público. De lo anterior deriva que, desde la legislación hasta ahora vigente, el principio de publicidad en nuestro proceso penal es relativo. los Jueces y Tribunales, mediante resolución motivada, podrán limitar el ámbito de la publicidad y acordar el carácter reservado de todas o parte de las actuaciones, claro está que esta reserva se refiere a la prensa o personas extrañas al proceso y no a las propias partes.

La secretividad o reserva a la que se alude en los procesos penales tiene por objeto -entre otras cosas- la preservación de las huellas del delito, recoger e inventariar los datos que basten para comprobar su existencia y reunir los elementos que más tarde han de utilizarse en la etapa plenaria.

La publicidad en este sentido surge de la esencia de nuestra Constitución Política como una de las garantías judiciales básicas que se relaciona con una de las funciones propias de la justicia penal: la transmisión de mensajes a la sociedad, acerca de la vigencia de los valores sociales que fundan la convivencia social. Como sabemos, una de las funciones de la norma penal es la prevención general de delitos ${ }^{25}$, es decir la producción de efectos sociales a través del castigo. Estos efectos sociales se pueden producir infundiendo miedo o intimidando a las personas para que no realicen las conductas prohibidas, estos efectos también pueden ser producidos por la afirmación pública de que existen ciertos valores que la sociedad acepta como básicos y que las personas deben autolimitarse en afectarlos, ya que, si esto sucede, si se cae en la prohibición o se incumple el mandato, podría adjudicársele la imposición de un castigo. Pese a todo debe reconocerse que en la tradición procesal nicaragüense la publicidad, como mecanismo de motivación o prevención general, no satisface las expectativas planteadas por el establecimiento de este principio, pues la concurrencia de los ciudadanos a los juicios es una visión de cierto modo superficial en la que la publicidad como proyección social queda reducida a lo que la prensa quiera publicar con una mayor o menor cuota de amarillismo produciendo, en algunas ocasiones, efectos contraproducentes.

El juicio público como expresión del principio de publicidad procesal implica un modo particular de insertar a la justicia en el medio social: implica que ella cumple con su tarea de transmitir mensajes sociales sobre la efectiva vigencia de los valores que fundamentan la convivencia social.

\footnotetext{
${ }^{25}$ Al respecto, LUZÓN PEÑA, Curso, 1996, 69.
} 
Acorde con lo establecido por la norma constitucional el sistema procesal vigente limita determinados actos procesales, así, la confesión se tomará reservadamente, y no podrán estar presentes otras personas distintas al juez, reo y secretario (art. 196 In.), en los casos en donde el juez considere que la intimidad de las personas y el interés de los menores en particular está en juego podrá decretar que las actuaciones se realicen en privado y a puerta cerrada por exigirlo así razones de moralidad y orden público, o el respeto debido a la persona ofendida y/o a su familia; debe entenderse pues, que el conocimiento del proceso está vedado al público, y a terceros no personados en él. Contrario a lo expuesto, la deposición de testigos se realizará en audiencia pública, con citación y en presencia del reo, su defensor, del fiscal y del acusador, si lo hubiere y quisiere concurrir, éstos y el juez pueden hacerles preguntas y reconvenciones que sean conducentes al esclarecimiento de los hechos sin ligarse a los interrogatorios (art. 211 In.). De la misma manera. en aquellos delitos cuyas penas sean más que correccionales, para los que se encuentra establecido el conocimiento del Tribunal de Jurados, la sesión que con ese efecto se practica deberá ser pública en el sentido amplio de la palabra (art. 274 y ss., 292 In.).

El nuevo Código Procesal Penal amplía un poco más la aplicación y operatividad del principio de publicidad, se trata de un juicio oral y público, debe reconocerse, sin embargo, que la publicidad continuará, por las razones señaladas en la propia Constitución, siendo relativa ${ }^{26}$. En este sentido el artículo 285 del CPr. establece: "El Juicio será público. No obstante, el juez podrá restringir el dibujo, la fotografía o la filmación de los miembros del jurado, de algún testigo o perito, y regular los espacios utilizables para tales propósitos".

"Excepcionalmente y con carácter restrictivo, el juez podrá resolver que se limite el acceso del público y de los medios de comunicación al Juicio por consideraciones de moral y orden público. cuando declare un menor de edad u otros casos previstos por la le $y^{27}$. La resolución será fundada y se hará constar en el acta del Juicio",28.

De todo lo anterior puede desprenderse que el derecho a un juicio público no es un derecho que pueda predicarse para todas las etapas del proceso, y tampoco es un derecho absoluto, así lo ha expresado la Declaración Universal de los Derechos Humanos del 10 de Diciembre de 1948, tras reconocer que toda persona acusada de un delito tiene derecho a un juicio público en el que se hayan adoptado todas las garantías necesarias para su defensa (art. 11.1), al mismo tiempo proclama que los derechos de la persona están sujetos a las limitaciones establecidas por la ley, con el fin de asegurar el reconocimiento y respeto de los derechos y libertades de los demás. y de satisfacer las justas exigencias de la moral, del orden público y del bienestar general (art. 29.2). En el mismo sentido se expresa el Convenio de Roma del 4 de Noviembre de 1950 (art. 6), y el Pacto Internacional de Derechos Civiles y Políticos de 1966 (art. 14.1).

${ }^{26}$ Concordante con ello puede confrontarse el enunciado expreso del artículo 13 CPr.

${ }^{27}$ También debe tenerse en cuenta las limitaciones establecidas por el artículo 286, a saber: "Por razones de disciplina y capacidad de la sala, el juez podrá ordenar el alejamiento de personas o limitar la admisión a determinado número".

${ }^{28}$ Desaparecida la causa de la restricción, se hará ingresar nuevamente al público. El juez podrá imponer a las partes el deber de guardar secreto sobre los hechos que presenciaron o conocieron, y así se hará constar en el acta del Juicio (Cfr. art. 285 CPr.). 
La práctica y experiencia tanto de nuestro proceso como el de otras legislaciones han demostrado que la publicidad del proceso al que alude el artículo 34 parte final de nuestra Constitución Política, debe entenderse como un derecho relativo y en ningún momento absoluto, en este sentido, debemos decir que en la legislación vigente la publicidad, en sentido amplio, se reserva para la etapa plenaria, concretamente en el momento posterior a la integración del jurado, o, en el nuevo proceso penal, para la etapa del juicio oral ${ }^{29}$. Tanto en uno como en otro el conocimiento de la causa durante el período de investigación o sumario puede limitarse únicamente a las partes procesales.

\section{Principio de oralidad}

Según BINDER $^{30}$ la oralidad como principio se establece como un mecanismo previsto para garantizar ciertos principios básicos del juicio penal, en especial el principio de inmediación, la publicidad del Juicio y la personificación de la función judicial. La oralidad representa, fundamentalmente, un medio de comunicación: la utilización de la palabra hablada, no escrita, como medio de comunicación entre las partes y el juez y, como medio de expresión de los diferentes órganos de la prueba.

Cuando BINDER se refiere a la palabra hablada como medio de comunicación señala que con ésta se desarrolla un mecanismo simple: en principio las personas tienen que estar presentes (inmediación) y, además, se comunican de un modo que es fácilmente controlable por otras personas (publicidad).

Aunque algunos juristas afirman que el juicio oral es demasiado complicado, la realidad demuestra -en palabras de JEREMÍAS BENTHAM- que es todo lo contrario, "el juicio oral explicaba- es el modo más natural de resolver los conflictos humanos e incluso así es el modo de administrar justicia en los grupos pequeños y la familia"31.

La oralidad es el principio procesal que permite no sólo la concentración del proceso, sino que garantiza la inmediación del órgano en todas y cada una de las etapas que para mejor garantía de los derechos ciudadanos deben realizarse, en una consideración tradicional se considera como un mecanismo que genera un sistema de comunicación entre el juez, las partes y los medios de prueba, y que al mismo tiempo permite descubrir la verdad de un modo más eficaz y controlado.

Al tratar de encontrar algún indicio del principio de oralidad en el proceso penal vigente observamos que por ser éste fundamentalmente inquisitivo, la mayoría de las actuaciones se realizan por escrito, mejor dicho, nuestro proceso penal es predominantemente escrito, así lo

\footnotetext{
29 Véase, artículo $287 \mathrm{CPr}$.

${ }^{30}$ BINDER, Introducción al DPP, 1993, pág. 96.

31 "En efecto a nadie se le ocurriría si tiene una controversia o un conflicto en su familia, formar un expediente, nombrar a uno de los miembros de la familia como instructor, levantar acta de los testimonios, pedirle por escrito de la opinión a cada uno de los miembros. En fin todas estas actividades que parecen ridículas y artificiosas en el contexto de un conflicto familiar, resultan igualmente artificiosas y ridículas cuando se trata de construir un proceso penal en el marco de una sociedad".
} 
establece el Código de Instrucción Criminal al señalar que el juicio criminal ordinario es escrito y se divide en dos partes: juicio de instrucción o informativo, y juicio plenario; el sumario es verbal y sólo tiene juicio de instrucción (art. 4 In) ${ }^{32}$.

En los sistemas procesales regidos por el principio de oralidad la actividad jurisdiccional propia de la fase de instrucción, reviste la forma connatural a las muy diferentes actuaciones que se realizan y se documentan por escrito, las alegaciones y recursos de las partes se formulan por escrito, y, por escrito se expresa el Juez en sus resoluciones; por lo que cabe afirmar que la escritura domina la primera fase del proceso; en la fase plenaria o juicio oral, debe predicarse la oralidad como de su propia denominación se desprende, so pena de nulidad.

Hasta ahora el proceso penal nicaragüense se había regido por la escritura en todas sus etapas, desde la recepción de la denuncia, o acusación en su caso. hasta la sentencia del órgano facultado para emitirla. Por el contrario, el nuevo Código Procesal Penal establece la oralidad con carácter general a través de la enunciación que de este principio realiza en el artículo 13, señalando que, so pena de nulidad. "las diferentes comparecencias, audiencias y los juicios penales previstos por este Código serán orales y públicos". Debe apuntarse, sin embargo, que el CPr. no se queda en esa mera declaración general, traduce ese enunciado en consecuencias concretas que se materializan en la realización del juicio oral y público.

En efecto, tal y como lo señala el artículo $287 \mathrm{CPr}$. "La audiencia pública se desarrollará en forma oral, tanto en lo relativo a los alegatos y argumentaciones de las partes como a las declaraciones del acusado. a la recepción de las pruebas y, en general. a toda intervención de quienes participen en ella. Durante el Juicio, las resoluciones serán fundadas y dictadas verbalmente en forma clara y audible por el tribunal y se entenderán notificadas desde el momento de su pronunciamiento, dejándose constancia en el acta del Juicio". Todo lo anterior no excluye la posibilidad de incorporar escritos durante el juicio, aunque en él deben ser leídos, básicamente se trata de pruebas preconstituidas o de diligencias realizadas fuera de la sala ${ }^{33}$.

\section{Principio de inmediación}

Cuando se habla del principio de inmediación se quiere hacer alusión a que los actos procesales deben practicarse ante el Juez. En el proceso penal vigente la inmediación por el órgano jurisdiccional constituye una excepción (caso de la inspección ocular), pues, como la mayoría de

$3:$ Cabe señalar que cuando nuestro código señala que el juicio sumario es verbal o que se procederá verbalmente, no se refiere desde ningún punto de vista a la oralidad, sino que hace alusión a lo expedito de las actuaciones desde el punto de vista formal.

${ }^{33}$ En este sentido la parte final del artículo 287 CPr. señala: "El principio de oralidad no excluye la posibilidad que durante el Juicio puedan ser incorporados para su lectura:

1. Las pruebas que se hayan recibido mediante la diligencia de anticipo jurisdiccional de prueba, sin perjuicio de que las partes o el tribunal exijan la comparecencia personal del testigo o perito, cuando sea posible:

2. La prueba documental, informes y certificaciones. $y$,

3. Las actas de las pruebas que se ordene practicar durante el Juicio fuera de la sala de audiencias. 
las legislaciones informadas por el principio de la escritura, la inmediación se ve corrompida por la delegación de los actos de investigación y recepción en el personal auxiliar del juzgado, en nuestra realidad procesal penal la mayoría de los medios probatorios como las testifícales o la confesión, que según la ley deben realizarse ante el juez de la causa, son practicadas, salvo raras excepciones, por el secretario del órgano (art. 157, 196 In.).

Como afirma BINDER en los procesos escritos, manifestación eminente del Sistema Inquisitivo, no existe un verdadero juicio porque no existe inmediación ya que el Juez sólo lee el expediente, no conoce a las partes, no escucha a los testigos y, además, desde que lee todas las actuaciones hasta que dicta la sentencia existe una ruptura de continuidad de modo que el juez se ocupa de otros asuntos y algunas veces ni siquiera lee el expediente sino que revisa un "proyecto de sentencia" que le ha preparado su secretario.

En la etapa plenaria del actual proceso penal el principio de inmediación puede observarse en la sesión pública del Jurado en donde el tribunal está obligado a formar su íntima convicción con relación al proceso que ante él se presenta por el titular del órgano jurisdiccional, y cuyo material probatorio ha podido formarse bajo su directa intervención; pero el principio de inmediación se desvirtúa cuando corresponde a un tribunal distinto, el tribunal de jurados, fallar sobre un asunto que justo en el momento de tomar la decisión acaban, si acaso, de conocer, es decir. que la causa es fallada por un Juez que no conoce la causa. En efecto, no se requiere ahondar demasiado para convencernos de que, en el actual sistema de jurados, la inmediación es inexistente, pues no podríamos llamar inmediación a la simple lectura de un expediente, por más que el secretario, lector del expediente, se aplique en su lectura jamás podrá trasladar a los restantes miembros del tribunal las emociones, sensaciones, angustias, mentiras y verdades expresadas en aquel momento en el que el testigo, la víctima o el procesado emitieron su declaración. En definitiva, no nos debe quedar la menor duda de que, en el actual sistema de jurados y en todo el proceso penal, el principio de inmediación no existe en la vigente legislación, ni desde el punto de vista formal y menos aún desde el punto de vista material.

Uno de los cometidos de la reciente reforma procesal es precisamente garantizar la vigencia del principio de inmediación, el juez o tribunal debe tener contacto directo con la prueba. debe escuchar a los testigos, a los peritos, a la víctima, al procesado, en otras palabras, acariciar la prueba a través de sus sentidos, formar su propio juicio basándose en los medios probatorios que ante él se han presentado. Es por ello por lo que tenemos que celebrar, pues constituye un gran acierto, que el nuevo Código Procesal Penal incorpore el principio de inmediación como base para la realización del juicio. "el Juicio se realizará con la presencia ininterrumpida del juez. todos los miembros del jurado en su caso, la parte acusadora, el acusado y su defensor..." señala el artículo $282 \mathrm{CPr}$.

Además de lo anterior. la propia norma es cuidadosa en señalar que "sólo podrá dictar sentencia el juez ante quien se han celebrado todos los actos del Juicio oral"34. De manera pues que la concreción realizada por la nueva ley no hace más que satisfacer, y de muy buena manera, una

\footnotetext{
${ }^{34}$ Cfr. art. 282 CPr.
} 
necesidad desde hace mucho tiempo sentida, la producción de seguridad jurídica que no se lograba a través de la incierta legislación vigente desde 1879 .

\section{A manera de conclusión. Las garantías del debido proceso en el nuevo Código Procesal Penal}

Con el objeto de asegurar al procesado y a las partes del proceso en general el disfrute de garantías que le permitan. en igualdad de condiciones, asumir conforme a la ley las resultas del proceso, la doctrina ha elaborado un sinnúmero de garantías que se traducen en las llamadas garantías del debido proceso y que señalan el acogimiento de los principios acusatorio, legalidad, oportunidad, publicidad, oralidad, inmediación, celeridad, entre otros.

Si bien el establecimiento de estos principios y garantías desde el punto de vista constitucional se traducen como derechos y garantías del procesado ${ }^{35}$-nos referimos a los principios de presunción de inocencia, el derecho a un juicio ágil y rápido, a un juez natural, al sometimiento de la causa ante un tribunal de jurados, al de intervención y defensa, a la asistencia de un intérprete si no comprende o no habla el idioma empleado por el tribunal, el de obtener una sentencia dentro de los términos legales, a no ser procesado nuevamente por el delito por el cual fue condenado o absuelto mediante sentencia firme, y a los de legalidad y publicidad del proceso-, es necesario. para asegurar su eficacia y respeto, que los mismos se encuentren establecidos y materialmente traducidos en la legislación ordinaria: esto no podía suceder en un sistema procesal penal que data del siglo XVIII y que necesitaba armonizarse con una Constitución que data del año 1987.

El enorme vacío - de legalidad y seguridad jurídica- que existía ante la dicotomía señalada, viene a ser cubierto. afortunadamente. por el nuevo Código Procesal Penal que incorpora todas las garantías del denominado debido proceso; basta con dar una ojeada a los primeros 17 artículos (los principios y garantías procesales) para constatar la vigencia en el futuro proceso penal de principios como el de legalidad (art. 1), presunción de inocencia (art. 2). dignidad humana (art. 3), derecho de defensa (art. 4), proporcionalidad (art. 5), única persecución (art. 6), y sucesivamente, gratuidad y celeridad procesal, intervención de la víctima. principio acusatorio, juez natural, sometimiento de la causa ante jurado, principio de oralidad, principio de oportunidad, de libertad probatoria. de la licitud de prueba y del derecho a la utilización de todos los recursos señalados en el cuerpo legal respectivo.

De manera pues que, dadas las condiciones en las que, desde el punto de vista normativo, se ha desarrollado el sistema de administración de justicia penal, el salto cualitativo operado a raíz de la aprobación del nuevo Código Procesal Penal, no hace más que ubicarnos a la par de la gran mayoría de legislaciones modernas, es decir, en el camino que conduce a la cima de la, tan anhelada, seguridad jurídica.

35 Véase el artículo 34 de la Constitución Política de la República de Nicaragua. 


\section{BIBLIOGRAFIA}

ARAUZ ULLOA, Manuel, Proceso Penal y Derecho Humanos en Nicaragua, Estudios Monográfico, Universidad Centroamericana, 1996. ARÁUZ ULLOA, Manuel/ MORENO CASTILLO, María Asunción, "La imagen de la Justicia”, editorial UCA, 2001. BINDER, Alberto. Introducción al Derecho Procesal Penal, 1a edición, Ad-hoc. Buenos Aires, 1993. LUZÓN PEÑA, Diego-Manuel, Curso de Derecho penal, Parte General I, Universitas, Madrid, 1996. MAIER, Julio. Derecho Procesal Penal Argentino, 2 edición, Hammurabi, Buenos Aires, 1989. DE LA OLIVA SANTOS, Andrés. Aragoneses Martínez, Sara. Hinojosa Segovia, Rafael. Muerza Esparza, Julio. Tomé García, José Antonio. Derecho Procesal Penal, Ramón Areces, Madrid, 1993. ZAFFARONI, Raul, en: Galván González, Francisco. Compilador: Eugenio Raúl Zaffaroni en Mexico, Archivo de Derecho Penal, $1^{\Perp}$ edición, Universidad Autónoma de Sinaloa, Sinaloa, 1993. 